\title{
Preparing Australia's Future LAWYERS: AN EXPOSITION OF Changing Values OVer Time In The CONTEXT Of Teaching AbOUt Ethical DILEMMAS
}

\author{
AdRIAN EVANS* AND JOSEPHINE PALERMO**
}

[This study investigated what values may be influential to decision making in relation to ethical behaviour for early career lawyers. It adopted a longitudinal approach to investigate how values develop or degrade over time as final year law students move into their first two years of employment or further study. To this end, the study investigated the role that tertiary education and employers fulfill in building and perpetuating 'appropriate' professional values? Results demonstrate that, in general, ethical behaviour was not uniformly reinforced over time in the workplace. The undertaking of pro bono work stands out here. Results suggested that certain behaviour relevant values may develop or degrade over the early years of the Australian lawyer's career. The implications of results are discussed in the contexts of ethics education in a tertiary context and the continuing education and regulation of the legal profession.]

\footnotetext{
* Associate Professor of Law at Monash University, Melbourne, Australia

${ }^{* *}$ Research Fellow, Deakin University, Melbourne, Australia This research is supported by an Australian Research Council Large Grant to Professor Evans, Professor Stephen Parker, former Dean of Law at Monash University, and Dr Palermo. We gratefully acknowledge with many thanks the efforts of Dr Matt Harvey, Consuela Catalini, Anna Kimm and Simon Miller, who have long laboured as Research Assistants in this study. The authors would also like to acknowledge the invaluable statistical advice provided by Dr Anthony Bedford of RMIT University.
} 


\section{INTRODUCTION}

Information about the values bases' of lawyers is critical for understanding the ways in which the broad justice agenda may maintain its relevance in the $21^{\text {st }}$ century. Lawyers are the actors of the justice system. Their motivating values, we assert, are therefore relevant to their support or degradation of justice. Commentary surrounding the behaviour of lawyers is increasing because of large law firms' involvement in highly public instances of unsatisfactory corporate behaviour. The latest of these cases is perhaps the least satisfactory. In Australia, James Hardie Industries, with the active cooperation of its in-house counsel and external lawyers, was found by the New South Wales Jackson Inquiry to have deliberately misled the community at large as to the reasons for its relocation of its corporate headquarters to the Netherlands, in order to avoid paying billions in additional compensation for asbestosis-related diseases caused, with its knowledge, by its building products. ${ }^{1}$ These war stories ${ }^{2}$ are often dismissed because they are sometimes

\footnotetext{
${ }^{1}$ James Hardie's lawyers were Allens Arthur Robinson, one of the big six Australian law firms. During the enquiry, Allens were asked why they had not stood back and asked themselves what they should be advising their client to do. Allens responded to the effect that that they were advising their client on the letter of the law, no more and no less. See Richard Ackland, 'Irresistible Charms' Business Review Weekly 30 September - 6 October 2004, 48. A succinct history of the Hardie affair, up until the appointment of David Jackson QC to investigate the matter, may be viewed in the Australian Parliamentary Library at www.aph.gov.au/library/pubs/rn/200405/05 rn12.htm (accessed 22 November 2005). The Jackson Inquiry (Report of the Special Commission of Inquiry into the Medical Research and Compensation Foundation, 21 September 2004, NSW Cabinet Office at www.cabinet.nsw.gov.au/publications.html, accessed 22 November 2005) was commissioned by the NSW Government in an attempt to discover who was responsible for the under-funding of the asbestosis compensation process. Commissioner Jackson considered that Hardie had misled the community as to its true purpose in relocating to the Netherlands: 'The second observation concerns the quite misleading statements made on behalf of JHIL at the time of separation, and the culture of denial adopted as the shortcomings in the Foundation's funding began to emerge. For nearly thirty years in this country we have had standards for business communications. Such communications are not to be misleading or deceptive. In my opinion they were not here observed.' (Part A, 13 [1.26]). The attempt by Hardie to avoid extensive financial obligation to its former employees and other users of asbestos products, is still unresolved. The NSW Government advised the company that it had until Saturday 26 November 2005 in which to finally agree to pay compensation, after which NSW would legislate to apply Hardie subsidiary company
} 
seen as 'one offs' and not demonstrable of any wider reality. While anecdotes might influence politicians, they do not necessarily persuade Law Deans or the profession that systemic problems are involved. Even the recent findings of the $H I H$ Royal Commission, which included a call for renewed vigour in tertiary ethics education, ${ }^{3}$ have not obviously affected either the learning priorities of law schools or the approach that the profession takes to dealing with disciplined practitioners.

assets to the compensation process. See Jonathan Porter and Jack Schmidtke 'Week Till Hardie Forced to Settle', The Australian (Sydney), 22 November 2005, 7. See also Chris Merritt, 'Options Canvassed For Hardie Law Changes', The Australian Financial Review (Sydney) 12 November 2004, 59. The willingness of the NSW government to enact special legislation to retrospectively compel Hardie to pay the additional compensation, is still to be tested. One view is that the Federal Government, despite its criticisms of Hardie's actions, would not permit such legislation to proceed because of its potential negative effect on foreign investment. See Ean Higgins, 'Iemma's Bid to Be The Dragon Slayer', The Weekend Australian (Sydney), 26-27 November, 29.

${ }^{2}$ Note this comment by Justice Neville Owen concerning the involvement of lawyers in the recent HIH implosion: 'The Lawyers: HIH approached various legal advisers from time to time to provide guidance on particular matters. There were occasions when the legal advice given fell short of what one would expect in the circumstances. One such occasion involved the provision of advice in a situation where the potential for a conflict of interest was obvious. Another entailed advice that sought to explain how to effect an arrangement in a way that would "get around" certain provisions of the Corporations Law that otherwise prohibited the arrangement. It is also disappointing that lawyers were among those involved in what I call the "dash for cash" in the days leading up to 15 March 2001.' HIH Royal Commission, The Failure of HIH Insurance, (2003), Vol 1, pp xiii-lxv available at $<$ http://www.hihroyalcom.gov.au/finalreport/index.htm> (accessed 21 November 2005).

${ }^{3}$ See above $\mathrm{n} 2$. In his comments from a personal perspective, Justice Owen said: 'Right and wrong are moral concepts, and morality does not exist in a vacuum. I think all those who participate in the direction and management of public companies, as well as their professional advisers, need to identify and examine what they regard as the basic moral underpinning of their system of values. They must then apply those tenets in the decision-making process. The education system - particularly at tertiary level - should take seriously the responsibility it has to inculcate in students a sense of ethical method'. (from HIH Royal Commission, The Failure of HIH Insurance, (2003), Vol 1 pp xiii-lxv) 
Post-Enron, some say that ethical sensitivity has become significantly more important to both business and the legal profession in western jurisdictions, but this is a doubtful proposition ${ }^{4}$. When things get tough, lawyers still retreat into the bunker, with the statement that 'ethics are no more than what the law requires. ${ }^{5}$ The reality, that legal ethics is/are considerably more than what the law requires, is confronting because such a focus requires an adherence to notions of justice which can edge out some powerful client demands. The actual relationship between the quality of justice and the values and behaviour of its (legal) practitioners is accordingly of obvious importance to an international 'justice priority', arguably even more so, now that we are facing a painful choice between whether or not to fully support the Rule of Law, within a 'War on Terror' context.

Law schools have generally assumed homogeneity in values and it has suited the profession to go along with this view. An initial task in our investigation was to establish whether there is an empirical basis for the assumption that lawyers' aspirations are based on shared personal and professional values. Having established that this assumption is empirically incorrect, ${ }^{6}$ we then need to ask 'what role does education play in the reinforcement of personal values appropriate for the legal profession?' and, 'what attitude can the profession play to values, in the post-admission context?'

In some countries the role of the university as nation builder is clearly understood. For example, in South Africa universities are mandated to enact their moral force to "contribute to the socialisation of enlightened responsible and constructively critical citizens. ${ }^{77}$ Australia has now followed the UK and US, through a major Values Education Study in the promotion of values education in primary school curricula to explicitly 'teach about values', to 'promote students understanding and knowledge of values and to inculcate the skills and dispositions of students so that they can enact particular values as

\footnotetext{
${ }^{4}$ See, for example, Leon Gettler, 'Just a Degree of Smoothing Means More Enrons Will Come: Author', The Age, Business, (Melbourne), 3 October 2005, 3, which confirms the prospects for further Enron-Like collapses.

${ }^{5}$ David Wighton and Andrew Parker, 'SEC Boss Hits Back at Critics of Reform', The Australian (Sydney), 21 September 2004, 25.

${ }^{6}$ Adrian Evans and Josephine Palermo, 'Lawyers' Perceptions of their Values: An Empirical Assessment of Australian Final-Year Undergraduate Law Students - Some Interim Results - 2001' 5 Legal Ethics 1\&2, 102-129.

${ }^{7}$ Vic Zbar, David Brown, and Barbara Bereznicki, (2003) Values Education Study (Report to Department of Education Science and Training).
} 
individuals and as members of the wider community" ${ }^{8}$. Values education work is continued to some extent in universities in Australia, particularly through graduate skills and ethics programs, ${ }^{9}$ however it is at best intermittent across the higher eduction sector and uncoordinated at the national or professions level. In other words, the impact of post-secondary education on values development and ethical understandings in the preparation of lawyers, teachers, engineers, scientists and business professionals is unknown.

The influence of personal values on decision making has recently been recognised as an integral factor in theories of managerial decision making ${ }^{10}$. Research indicates that values predict world views, hence having great potential to predict behaviours in work places and around issues of social justice and political orientation Research that has studied the relationships between values, attitudes and behaviours indicate that there is a weak direct relationship between values and behaviours ${ }^{11}$. However there is evidence of strong relationships between values and behaviour relevant attitudes. ${ }^{12}$ These include attitudes towards civil rights, international affairs, religion, political activism, choice of academic area etc. ${ }^{13}$

We speculate that lawyers who subscribe to values which emphasise the importance of wealth creation or employer loyalty (above all else) may be inclined to behave consistently with those attitudes within their professional environments. Issues of social justice and ethical decision-making may therefore at times run counter to models of decision making in some firms and institutions.

\footnotetext{
${ }^{8}$ Ibid.

${ }^{9}$ Efforts to integrate values and ethics awareness in a multi-cultural, multi-faith context are under way. See for example Ray Elliott 'A Skills and Knowledge Grid for the Domains, Sources and Methods for Ethical Decision-Making in a Multi-cultural Pluralist World' (Chapter in R Elliott and M Tuohy, Ethics and Morality in a Multicultural Society, (2005)).

${ }^{10}$ William E Shafer, Roselyn E Morris, and Alice A Ketchand, 'Effects of Personal Values on Auditors' Ethical Decisions' (2001) 14(3) Accounting, Auditing \& Accountability Journal 254.

${ }^{11}$ Milton Rokeach and Sandra J Ball-Rokeach, 'Stability and Change in American Value Priorities 1968-1981' (1989) 44(5) American Psychologist 775.

${ }^{12}$ Zowie Wharton and Howard.R. Harmatz, 'Responses to the Economy Among Two Value Orientation Segments' (1995) 16 Journal of Economic Psychology 205.

${ }^{13}$ Ibid 8.
} 
While studies on the direct relationship of personal values and behaviour have been mixed, the existence of gender differences in value hierarchies of men and women is evidenced in a plethora of studies. For example, Hotel ${ }^{14}$ who interviewed 36 lawyers predominantly practicing in family law, found that men were less likely to identify moral conflict in a particular scenario because they were more likely to identify fully with their professional role. Their vocational identity was that of 'hired gun' where they perceived no greater obligation than that to the client, thus abdicating any moral or ethical responsibility to themselves. Droddy and Peters ${ }^{15}$ found that United States female law students are more liberal (less politically conservative) than their male colleagues and were indeed more liberal than most female University students. This confirms an earlier study by Krierie $^{16}$ who also found significant differences between male and female students in their assessment of ethical and un-ethical behaviours. She found that women tended to be more ethically conservative, and were more likely to consider environmental cues as well as their personal values.

There is little systematic effort within the organised profession ${ }^{17}$ to address lawyers' behavioural motivation and it may be that this deficiency will never be adequately addressed unless there is both clear information ${ }^{18}$ as to the extent of the problem and a viable methodology to address it. We conclude

\footnotetext{
${ }^{14}$ Cited from Ian.N McCarthy, 'Professional Ethics Code Conflict Situations: Ethical and Value Orientation of Collegiate Accounting Students' (1997) 16 Journal of Business Ethics 1467 - 1473.

${ }^{15}$ J D Droddy and C S Peters, 'The Effects of Law School on Political Attitudes: Some Evidence from the Class of 2000' (2003) 53 Journal of Legal Education 1, 33 47.

${ }^{16}$ Jennifer Kreie and Timothy P. Cronan, 'How Men and Women View Ethics' (1998) 41 (9) Communications of the Association for Computing Machinery 70.

17 'Role Play the Order of the Day', Lawyers Weekly (Australia), 7 March 2003, 1 \& 7, describes an exceptional initiative of the Law Institute of Victoria (LIV) in that year. The LIV has introduced the concept of the Designated Ethics Practitioner (DEP) who handles in-house ethical queries in participating firms (the largest and major players are all involved) and attends peer review sessions - known as the Ethics Liaison Group (ELG) sessions - which use hypotheticals as a training tool - on a regular basis.

${ }^{18}$ Empirical investigations as to the extent of the likely 'values drought' have been under way in Australia for some years (see Adrian Evans and Josephine Palermo, 'Lawyers' Perceptions of their Values: An Empirical Assessment of Australian FinalYear Undergraduate Law Students - Some Interim Results - 2001' 5 Legal Ethics $1 \& 2,102-129)$. It is also likely that pilot research programs will be under way in the United Kingdom and the United States in the foreseeable future.
} 
this article with some suggestions for such a methodology, based upon the insights achieved from an empirical research process into Australian law students' and lawyers' value systems.

Over the period 2001-2003 a large group of Australian final-year undergraduate law students/early year practitioners were surveyed in a longitudinal study of Australian lawyers' values. This larger study was undertaken to understand what values are empirically important in determining lawyers' attitudes to difficult behavioural choices confronting them in legal practice. Specifically the present study investigated change over time of these behavioural choices and behaviour relevant values in the early career of Australian lawyers. We also aimed to investigate any differences in

ethical responses and value orientations of males and females, and for early career lawyers who had completed an ethics subject and / or clinical placement during their law degrees.

\section{METHOD}

\section{A Participants}

Year 1: Law faculties across Australia were asked to assist in distributing surveys to students enrolled in the final year of their law degrees. 700 individuals responded to the mail questionnaire, representing approximately $18 \%$ of the population of 4000 Australian final year law students. All jurisdictions were represented in the final sample, although most respondents came from NSW, Victoria, and Queensland. Females accounted for 61 percent and males 39 percent of respondents. These proportions are quite close to the actual gender mix of Australian law students. 60 percent of the sample categorized themselves in the 18-25 years age group and 72 percent classified themselves as 'Australian'.

The majority of the sample were single (70\%) and had no children (84\%). Most had parents with professional, teaching, or business backgrounds. Based on the Australian Bureau of Statistics (Index of Education and Occupation) classification of socio-economic status 19 as derived from postcodes of residence, most of the sample was classified as residing in homes with a high socio-economic status classification (61\%).

${ }^{19}$ Genevieve Sinclair, James Doughney, and Josephine Palermo, 'Equity indicators: Measures of socio-economic status at an Australian University’ (2003) 12(1) Journal of Institutional Research 74. 
Nearly $70 \%$ of respondents had completed an "ethics" course and might therefore be thought to have had some exposure to the ethical issues of practice, while only $40 \%$ had experienced a "clinical" course in law. Overall, the sample was representative of the population of law graduates in Australia.

Year 2: Year 1 respondents who had indicated their consent to participation in the longitudinal study were contacted via email, phone or by mail. 412 participants returned completed surveys in year 2 (conducted on paper or online). The sample characteristics mirrored these of the sample in year 1 . Variations from this were that females accounted for a slightly higher proportion of the sample $(64 \%)$ and more of the younger participants continued with the study in year $2(56.4 \%)$. Table 1 presents the distribution of occupational classifications of the sample in the second year of the study. It shows that the majority of the sample had gained employment in legal practice / law and business settings.

Year 3: 362 participants returned completed surveys in year 3 (returned by mail or on-line). Sample attrition appeared to be spread evenly across characteristics of the sample so that the year 3 sample appeared well representative of the sample in year 2 .

Table 1

Distribution of participants into occupations in the second year of the study (i.e. year after graduation)

\begin{tabular}{lll}
\hline Industry & Frequency & Valid \% \\
\hline Academic /Teacher & 8 & 2.27 \\
Accountant & 9 & 2.55 \\
Admin / Public service & 20 & 5.67 \\
Business & 17 & 4.82 \\
Health & 5 & 1.42 \\
Legal practice / Law & 231 & 65.44 \\
Science and Computing & 7 & 1.98 \\
Army & 2 & 0.56 \\
Student & 43 & 12.18 \\
Unemployed & 7 & 1.98 \\
Farmer & 1 & 0.28 \\
Police & 1 & 0.28 \\
Policy & 2 & 0.56 \\
\hline Total & & \\
\hline
\end{tabular}




\section{B Procedure}

To examine the effects of value ratings on ethical decision making, it was necessary to situate respondents' responses within contexts that provided for ethical dilemmas. The survey utilised an oblique measurement of law students' values, based upon responses to survey questions which were piloted in a 1998 survey of Monash law graduates ${ }^{20}$. Rather than directly ask students about their values, we deployed the practice of the hypothetical situation, adding a personal dimension to further reduce the level of abstraction and assist in actual values identification.

Although 11 scenarios were presented to participants in the larger longitudinal study only 5 are included in this paper. These scenarios were deemed most challenging and confronting by participants in a qualitative study, that utilised focused groups with the same participants ${ }^{21}$.

These few scenarios which posed a clash of competing, individualistic values tended to evoke quite polarised discussion about conventional legal ethical positions. The child protection scenario is a case in point. The pervasiveness of client confidentiality as a cornerstone of solicitor/client relations, contrasted with the simultaneous acknowledgment that a child's life may be in jeopardy as a result of that confidentiality, heightened the intensity of decision and subsequent discussion in the focus groups. ${ }^{22}$ Both client confidentiality and child protection appear to be altruistic motivations in the sense of being less self-oriented, however, interviewees' attachment to both positions often seemed driven by some degree of self-protection. Thus, decisions to report suspected child abuse were tinged with fear of 'not being able to live with oneself'. Similarly, maintenance of client confidentiality was seen as preventing potential reputational damage in the event that suspicions of harm were unfounded, or the hypothetical client attempted to take action for breach

\footnotetext{
${ }^{20}$ Adrian Evans, 'Lawyers' Perceptions of their Values: An Empirical Assessment of Monash University Graduates in Law 1980-1998' (2001) Legal Education Review 2 (1\&2) 219.

${ }^{21}$ Adrian Evans and Josephine Palermo, 'Zero Impact: Are Lawyers' Values Affected by Law

School?' (2006) 8(2) Legal Ethics 214.

${ }^{22}$ Ibid. A discussion of the focus group reflections does not appear here for reasons of space but will be integrated to final quantitative results in a concluding monograph, in due course.
} 
of confidentiality. More details about the full study are available in previous publications by the authors. ${ }^{23}$

Participants were asked to indicate their probable behaviour in each scenario. After reflecting on their decision, they were also asked to weight the importance of a number of behaviour relevant values (BRVs), (on a scale ranging from $1=$ not important to $5=$ very important). Since the scenarios were also relatively commonplace, it was reasoned that a degree of personal identification with the lawyer's dilemma (in each scenario) would emerge.

\section{Analysis}

Results are presented for scenarios involved in the study were compared across the 3 years of the study. Cross tabulations and tests of independence (Chi Squared) were also conducted.

To ascertain the magnitude of change in results from one year of the study to the next, Kappa coefficients were produced. Kappa is a useful statistic for describing the magnitude of change over time ${ }^{24}$. The coefficient is a measure of association or correlation between variables measured at the categorical level. In this study, the coefficient denotes the proportion of agreement between an individual's response in yearl and their response in year $1+\mathrm{n}$ after chance agreement has been excluded. In other words, it describes the level of agreement or disagreement of an individual's response from one year to the next, with an upper limit is +1.00 (total agreement). All Kappa coefficients presented denote significant associations. Associated cross tabulations and Chi Square statistics are available on request.

\footnotetext{
${ }^{23}$ Adrian Evans and Josephine Palermo (2002) ‘Australian Law Students' Perceptions of their Values: Interim results in the first year -2001 - of a three year empirical assessment', (2002) 5 (1-2) Legal Ethics 103. Adrian Evans and Josephine Palermo, 'Gender and Ethics', (2005) 79 (10) Law Institute Journal 40.

${ }^{24}$ For more information about Kappa see Leon Becker 'Crosstabs: Kappa' (1999) http://www.uccs.edu/becker/SPSS/ctabk.htm sourced 1/12/2004; Helena Chmura Kraemer, Vyjeyanthi S Periyakoil and Art Noda 'Tutorial in Biostatistics: Kappa Coefficients In Medical Research’ (2002) 21 Statistics in Medicine, 2109.
} 
III RESULTS

\section{A Changing responses to reported behaviour over time}

\section{Figure 1 - Percentage 'yes' responses for each scenario across time}

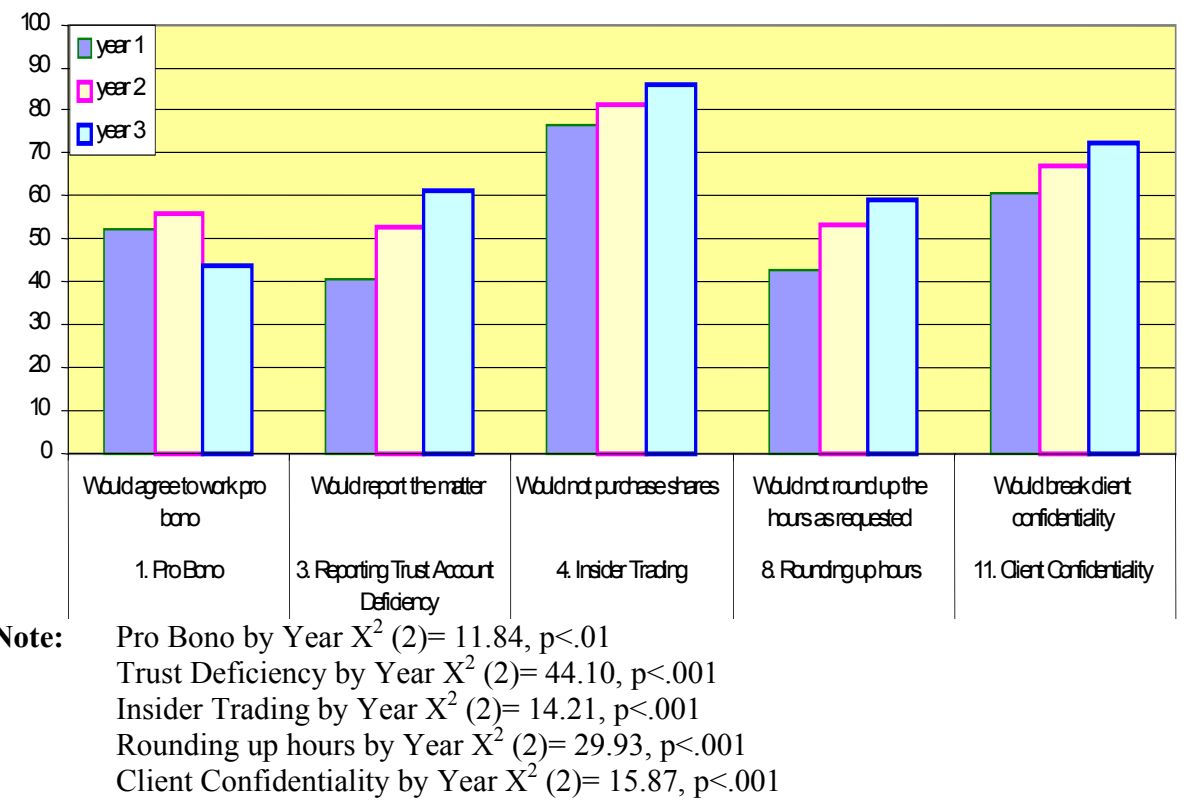

Figure 1 displays the proportion of 'yes' responses in the five chosen scenarios for all participants in the three years of the study. Chi Square tests were performed on differences between frequency distributions of reported behaviour across the three years of data. Results suggest that differences in frequency distributions over time were statistically significant.

\section{Pro Bono Scenario}

Scenario 1: You are a new solicitor working in a large commercial law firm. A voluntary public-interest organisation approaches you to work on a prominent test case about women who kill in self- defence. Your interest in this area is well known. The work would be pro bono and very high profile for you personally but of little interest to your firm. The matter requires a lot of time and work. Your senior partner however wants you to increase your billable hours for the firm. The firm does not usually do any pro bono work 
but there is no actual policy against it. Your time is currently so limited you could only realistically do one or the other. Would you agree to work on the public interest case?

In their final year of Law School, a little over half of the respondents reported that they would agree to work pro bono in Scenario 1. Whilst there was a slight increase of respondents reporting they would agree to undertake the pro bono work in year 2, responses decreased in year 3. This suggests that some respondents changed their minds in a negative direction.

Analyses of cross tabulations of these responses by groups of participants and tests of independence elucidated some interesting results. They showed that there were significant differences between responses of males and females, with females more likely to indicate a significant positive response, particularly in year $2\left(\mathrm{X}^{2}(2)=12.95, \mathrm{p}<.01\right)$.

In order to investigate the extent to which patterns of change in values influenced reported behaviour Kappa coefficients were produced and are displayed in Table 2. Kappa coefficients in Table 2 suggest that there were variations in levels of agreement across the three years of the study on some BRV's.

Table 2

Kappa coefficients for BRVs related to Scenario 1 - Pro Bono

\begin{tabular}{lll}
\hline & Level of Agreement (Kappa) \\
\hline Behaviour Relevant Value & Year 1-3 & Year 2-3 \\
\hline Business efficacy & .11 & .22 \\
Employer loyalty & .07 & .24 \\
Access to justice & .22 & .25 \\
Professional ambition & .15 & .25 \\
Employment security & .19 & .16 \\
\hline
\end{tabular}

Results showed that there was a higher level of agreement in the importance of 'business efficacy', 'employer loyalty' and 'professional ambition' between years 2 and 3. For example, the Kappa coefficient increased to .22 between years 2 and 3, suggesting that there was double the level of agreement between responses in years 2 and 3, than across overall responses. This suggests that respondents changed their minds about the impact of these values from that originally reported in year 1 . This result can be contrasted to those produced for 'employment security' and 'access to justice' where kappa coefficients were similar, suggesting that the level of agreement about the 
importance of these BRV's remained consistent across all three years of the study.

Whilst Kappa coefficients suggest that BRV's were rated differently across years 1-2 and 2-3, they do not tell us anything about the direction of that change. Therefore to further investigate the direction in which BRV's change over time, mean differences were plotted for those BRV's with differing Kappa coefficients between these time frames. Figure 2 displays mean difference plots for 'business efficacy', 'employer loyalty' and 'professional ambition'.

\section{Figure 2}

Mean differences and 95\% confidence intervals for Scenario 1 (Pro Bono) BRVs that appear to change over time
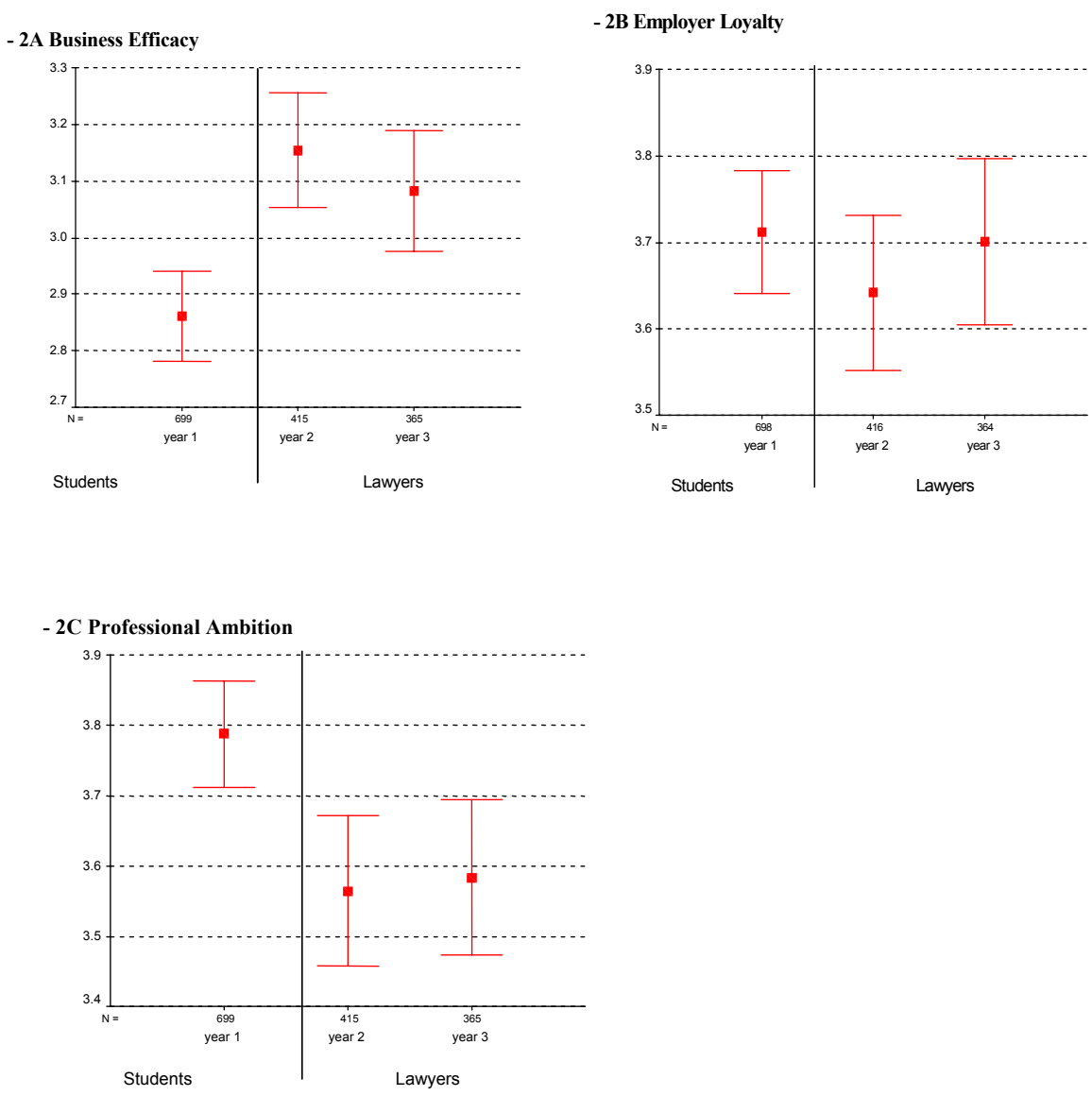
Trends suggested in Figure 2 show that the importance of 'business efficacy' increased over time, whilst the importance of 'professional ambition' and 'employer loyalty' decreased. This may be related to the decrease in reported choice to undertake pro bono work over time.

Pro bono activity may be considered a primary indicator of a professional attitude. Indeed, some writers are adamant that the quality of 'altruism' which for the purposes of this study we have compacted somewhat into a forced choice about whether to give something to the community or not - is an archetype of professionalism ${ }^{25}$. However results for the Pro Bono scenario were concerning. The attitude of a majority of participants in year 3 suggested a further hardening: respondents were even less likely to take on pro bono work. The attitude towards pro bono work appeared to be eroded in the post-secondary environment, with values associated with business efficacy appearing to become more salient in this period.

\section{Trust Deficiency Scenario}

Scenario 3: You are a Partner in the firm of AMBD. Your nephew (the son of your elder sister) is an associate in the firm. You discover your nephew has a minor gambling problem and has taken money from the firm's trust account to cover his debts. Fortunately you discover the problem in its very early stages. Your nephew is now undergoing counselling for his gambling addiction and appears to be recovering. The amount missing from the trust account is relatively small and you are certain could be reimbursed without attracting any attention. Would you report the matter to the local law society?

Only 40 percent of respondents in their final year of Law School reported that they would report the trust deficiency in this scenario. However this proportion increased to a half of respondents in year 2 and 60 percent of respondents in year 3. This suggests that (thankfully) some respondents changed their minds during their transition and adjustment experiences from university to employment.

\footnotetext{
${ }^{25}$ See Theresa Glennon, 'Lawyers and Caring: Building an Ethic of Care into Professional Responsibility' (1992) 43(4) Hastings Law 1175; Anthony Kronman, 'Professionalism' (1999) 2 Journal of the Institute for the Study of Legal Ethics 89; James Gobbo, 'Idealism under Stress: Legal Practice in Victoria' (2000) 12 Law Institute Journal 85; Roger K. Warren, 'Transcript from Professionalism Conference' (2001) 52(3) South Carolina Law Review 489 - 490; Noel Preston, Understanding Ethics, (2 ${ }^{\text {nd }}$ ed, 2001) 58-62.
} 
Analyses of cross tabulations of these responses by groups of participants suggested that there were significant differences between responses of males and females, with females more likely to indicate a positive response, particularly in year $1\left(\mathrm{X}^{2}(2)=19.43, \mathrm{p}<.001\right)$.

Table 3

Kappa coefficients for BRVs related to Scenario 3 - Trust Deficiency

\begin{tabular}{lll}
\hline & \multicolumn{2}{l}{ Level of Agreement (Kappa) } \\
\hline Behaviour Relevant Value & Year 1-3 & Year 2-3 \\
\hline Personal obedience & Ns & .22 \\
Family loyalty & Ns & .26 \\
\hline
\end{tabular}

Kappa coefficients displayed in Table 3 suggested that there was no significant agreement between participants' responses in year 1 and their responses in year 3. However there were significant levels of agreement for responses between years 2 and 3 . This suggests that most participants in the first year of the study dramatically changed their response to the importance of these BRV's to their reported behaviour in the second year of the study, and that this then remained constant in the third year. In other words, the transition from law school to legal practice is associated with respondents changing their minds about the impact of these BRVs from those originally stated in their final year of law school, on the decision to report the trust deficiency in this scenario.

To further investigate the direction of this change over this time time, mean differences were plotted for the BRV's in Scenario 3. Figure 3 displays mean difference plots for 'personal obedience' and 'family loyalty'.

\section{Figure 3}

Mean differences and $95 \%$ confidence intervals for Scenario 3 BRVs that appear to change over time
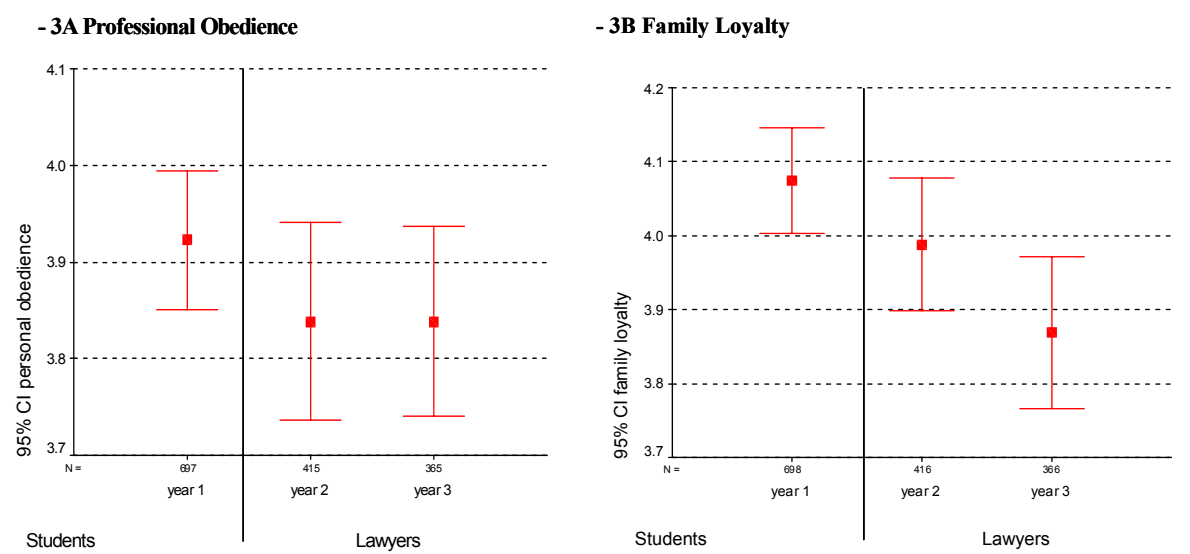
Graphs in Figure 3 suggest that the impact of these values, especially 'family loyalty', degraded over time. It is not surprising that for this scenario, values associated with 'personal obedience' and 'family loyalty' appeared to decline in importance as the propensity to choose to report the nephew increased over time. This relationship is in the expected direction, but it remains of concern that, after two years in legal practice, 40 percent of respondents would be prepared to 'cover up' a trust account deficiency.

\section{Insider Trading Scenario}

Scenario 4: Despite long hours and a great deal of work, you have been struggling for some months to make ends meet in your first couple of years as an employee lawyer. You have a HECS debt that you would like to clear and a close friend with whom you are very keen to move in and set up a home. A corporate client of your firm, for whom you have done some useful work, takes the partner responsible, yourself and others in your section to lunch to celebrate (confidentially) the award of a tender. You know that the client is grateful and wants to recognise your collective contributions to this particular success. The client CEO says as much and, in addition to the usual hints about more work, speculates off-handedly that the price of the company's shares is likely to reflect the win once it is all announced. Would you purchase shares in the company before the public announcement of the tender success?

The majority of participants in the first year of this study indicated that they would not purchase the shares prior to the public announcement. This proportion increased in years 2 and 3 to 86 percent.

Analyses of cross tabulations of these responses by groups of participants and tests of independence suggested that there were differences between responses by males and females. Females were more likely to increasingly report that they would not purchase the shares than were males over the course of the three years of the study $\left.\mathrm{X}^{2}(2)=10.82, \mathrm{p}<.05\right)$. To explore the level of agreement between participants' ratings of the importance of BRV's to their reported decision, Kappa coefficients were produced and are displayed in Table 4. 
Table 4

Kappa coefficients for BRVs related to Scenario 4 - Insider Trading

\begin{tabular}{lll}
\hline & \multicolumn{2}{c}{ Level of Agreement (Kappa) } \\
\hline Behaviour Relevant Value & Year 1-3 & Year 2-3 \\
\hline Employment security & .14 & .22 \\
Loyalty to the firm & .16 & .27 \\
Discomfort of information use & .26 & .29 \\
Commercial advantage & .16 & .21 \\
\hline
\end{tabular}

The Kappa coefficients in Table 4 showed that there was a higher level of agreement across all BRV's in the years after leaving law school, except for 'discomfort of information use'. In other words, law students' inherent and strong sense of anxiety about using confidential information continued into legal practice at a slightly stronger level and was not undermined by greater firm loyalty or even the prospect of commercial advantage. To further investigate the direction of this change over this time, mean differences were plotted for the BRV's in Table 4 that appeared to change inconsistently over time. Figure 4 displays mean difference plots for 'employment security', 'loyalty to the firm', and 'commercial advantage'.

Figure 4: Mean differences and 95\% confidence intervals for Scenario 4 BRVs that appear to change over time
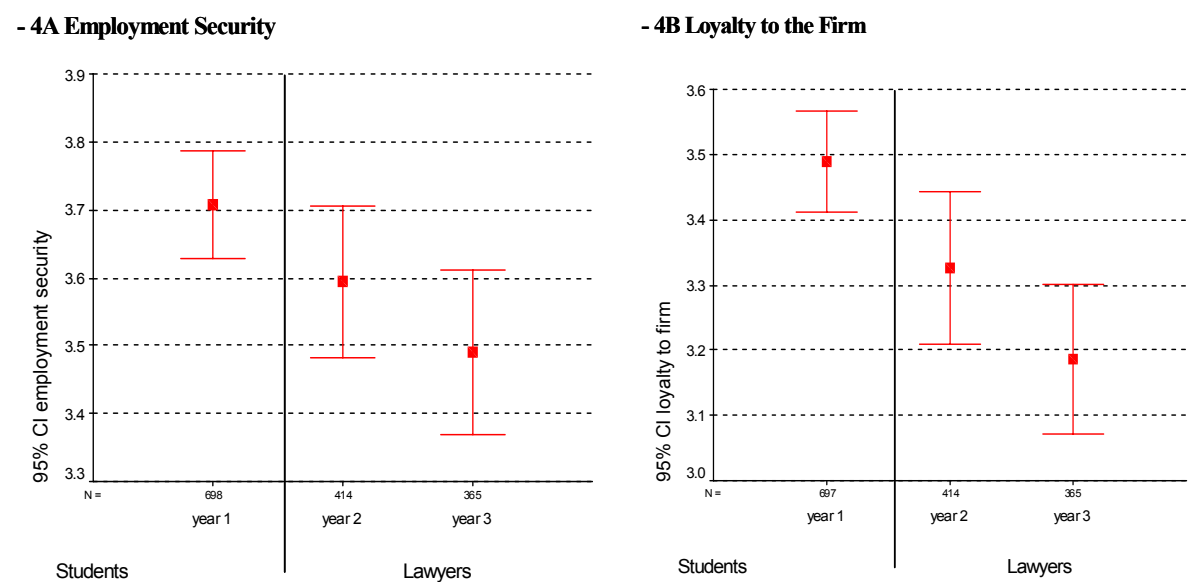


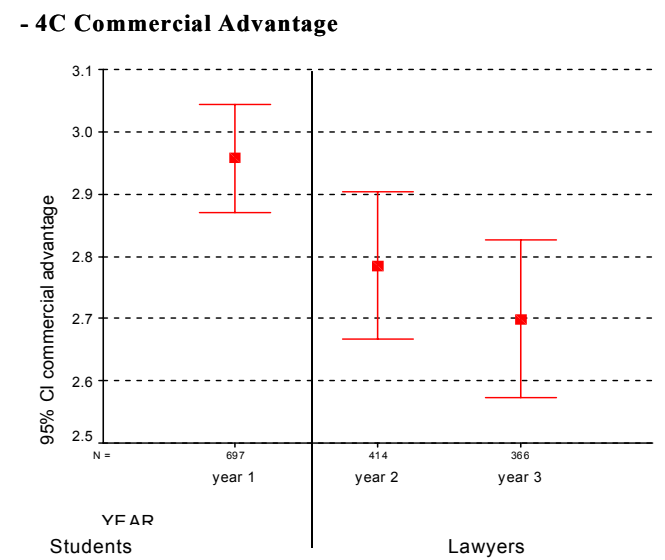

These results, taken together with Kappa coefficient trends, suggest that for participants, the importance of 'employment security', 'loyalty to the firm', and 'commercial advantage' decreased from that originally reported in year 1. This result, which of course predated the Steve Vizard insider trading failure of 2005,26 was encouraging evidence of participants' increasingly choosing to refrain from insider trading in this scenario over time.

\section{Rounding up Hours Scenario}

Scenario 8 - Rounding up hours: While on a summer clerkship with a large and well-respected commercial firm, you are (naturally) concerned to make a good impression. It is your second last year of law school and you are desperate for Articles. The partner supervising you decides to give you some of her files to get ready for 'costing'. She asks you to total the number of hours which she has spent on each file and, from her harried expression, it is pretty clear that she is concerned to charge out a significant amount on each file. She asks you to 'round up' her hours to the next hundred in each file, saying that, on average, clients are happy because the main thing they demand is quality work. You know that these clients are entirely satisfied with the firm and that your supervisor is not about to debate the issue with you. Would you round up the hours as requested?

\footnotetext{
${ }^{26}$ Steve Vizard, a Melbourne businessman, used inside information about the fortunes of software companies, which he gleaned from his seat on the Board of Telstra. See www.crikey.com.au/articles/2005/07/12-1612-7738.html.
} 
It is noteworthy that this scenario specified rounding up hours to the next 100, not just dollars. Only 40 percent of respondents in their final year of Law School reported that they would not round up the hours to the nearest 100 hours. However this proportion increased to a half of respondents in year 2 and 60 percent of respondents in year 3.

Analyses of cross tabulations of these responses by groups of participants and tests of independence suggested that there were differences between responses by males and females, particularly in year 2 . Females were more likely to report that they would not round up the hours $\left(X^{2}(2)=21.79, p<.001\right)$. To explore the level of agreement between participants' ratings of the importance of BRV's to their reported decision, Kappa coefficients were produced and are displayed in Table 5.

Table 5

Kappa coefficients for BRVs related to Scenario 8 - Rounding up hours

\begin{tabular}{lll}
\hline & \multicolumn{2}{l}{ Level of Agreement (Kappa) } \\
\hline Behaviour Relevant Value & Year 1-3 & Year 2-3 \\
\hline Employment prospects & .13 & .20 \\
Loyalty to the supervisor & .21 & .21 \\
Discomfort with request & .19 & .25 \\
Professional ambition & .15 & .16 \\
Client concern & .14 & .23 \\
\hline
\end{tabular}

Results in Table 5 showed that there was a higher level of agreement for BRVs 'employment prospects', 'discomfort with request' and 'client concern' between years 2 and 3 than between years 1 and 3. Kappa coefficients were clearly larger with these BRV's for Years 2-3, suggesting a larger degree of association between individual responses across this time. This suggests that respondents changed their minds about the impact of these values. Conversely, consistent Kappa coefficients for 'loyalty to supervisor; and 'professional ambition' across the three years of the study suggest that they played a similar part in participants' later-year decisions. To further investigate the direction of this change over this period, mean differences were plotted for the BRV's in Table 5 that appeared to change inconsistently over time. Figure 5 displays mean difference plots for 'employment prospects', 'professional ambition' and 'client concern'. 


\section{Figure 5}

Mean differences and $95 \%$ confidence intervals for Scenario $8 \mathrm{BRV}$ s that appear to change over time
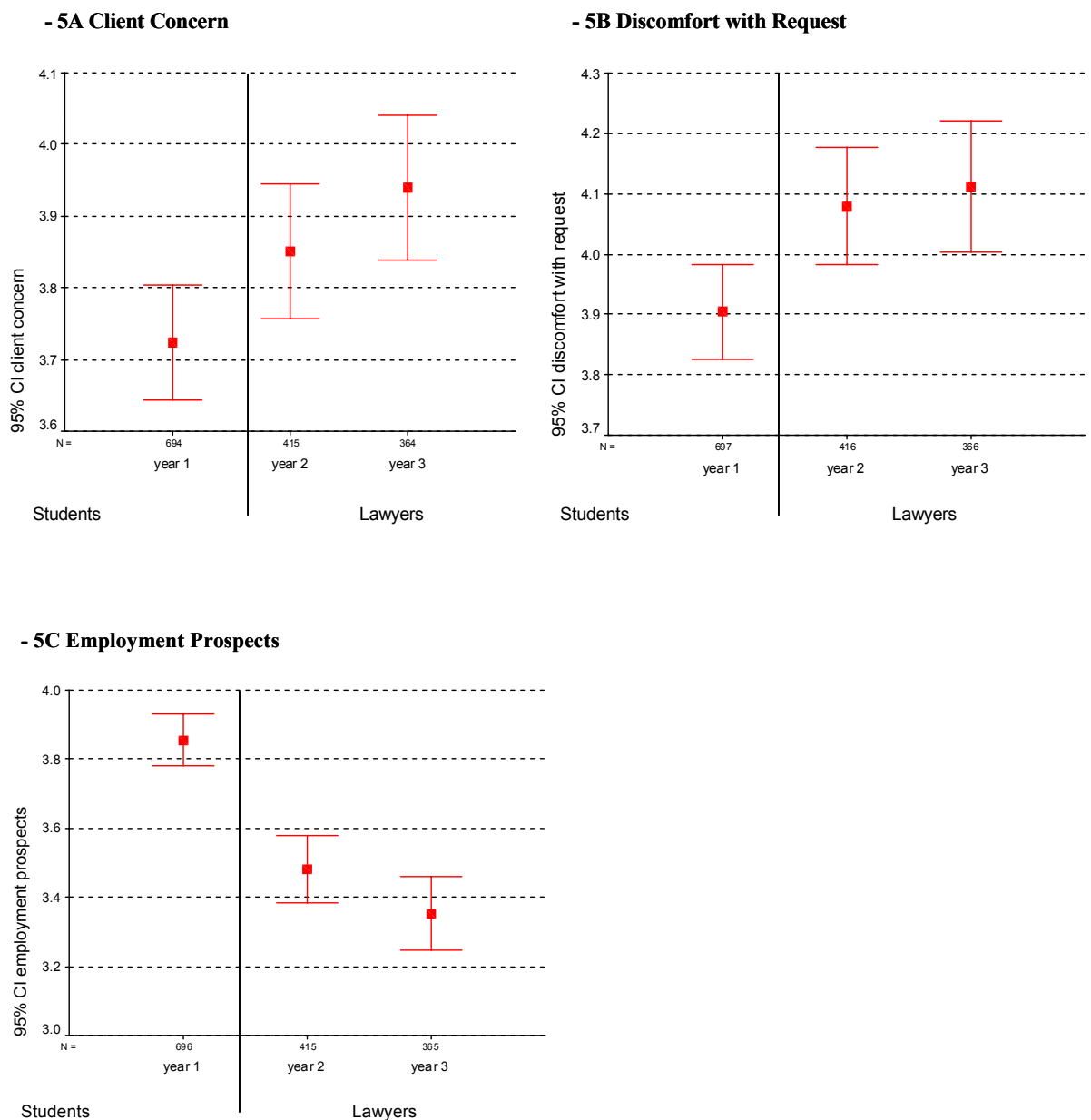

Figure 5 suggests participants were likely to degrade the importance of 'employment prospects' as an influencing factor in making a decision in this scenario. Conversely they were also likely to inflate, over time, the importance of their 'discomfort with the request' and 'concern for the client'. This result may be reflect greater concern for clients' rights than when the respondents were law students. 
Further, values associated with personal interest (employment prospects) and a more communal interest (concern for client) appeared to change in opposition to each other as the propensity to refrain from rounding up the hours to the nearest one hundred increased for participants over time. This may suggest that an increased concern for client welfare and decreased concern for personal interest may be related to the reinforcement of behaviour aligned to ethical codes of conduct in this scenario. Perhaps these values are important predictors of ethical conduct for this scenario as participants confront career-forming issues related to professional ethics and client relations.

\section{$5 \quad$ Client Confidentiality Scenario}

Scenario 11: You are acting for a mother of three small children in a divorce and intervention order matter. Your client has previously shown you some old photographs of bruises and marks on the children which she claims were inflicted not by their father, but by her new boyfriend. One of the children now has blurred vision. Your client now instructs you to stop all legal proceedings as she intends to return to the children's father with her children. You believe the children will be at risk if this happens but you know "mandatory reporting" does not apply to lawyers in your state. Would you break client confidentiality and inform the relevant welfare department of your fears?

Over 60 percent of respondents in their final year of Law School reported that they would break client confidentiality in this scenario. This proportion increased marginally to over 70 percent by year 3 . Analyses of cross tabulations and tests of independence suggested that were differences between responses by males and females across the three years of they study. Females were more likely to report that they would break client confidentiality than were males $\left(\mathrm{X}^{2}(2)=8.10, \mathrm{p}<.05\right)$. Kappa coefficients were produced and are displayed in Table 6 .

Table 6

Kappa coefficients for BRVs related to Scenario 11 - Client Confidentiality

\begin{tabular}{|l|l|l|}
\hline & \multicolumn{2}{|l|}{ Level of Agreement (Kappa) } \\
\hline Behaviour Relevant Value & Year 1-3 & Year 2-3 \\
\hline Client confidentiality & .09 & .12 \\
\hline Professional integrity & .10 & .08 \\
\hline Civic duty & .18 & .33 \\
\hline
\end{tabular}

Note: All Kappa coefficients presented denote significant associations. 
The higher Kappa coefficients for Years 2-3 for 'client confidentiality' and 'civic duty' in Table 6 suggests that participants changed their mind about the influence of these values when they began to experience work or further study. However the level of agreement between ratings of 'professional integrity' appeared to remain roughly consistent across the three years. To further investigate the direction of change over time for client confidentiality' and 'civic duty', mean differences were plotted and are displayed in Figure 6.

\section{Figure 6}

Mean differences and $95 \%$ confidence intervals for Scenario 11 BRVs that appear to change over time.
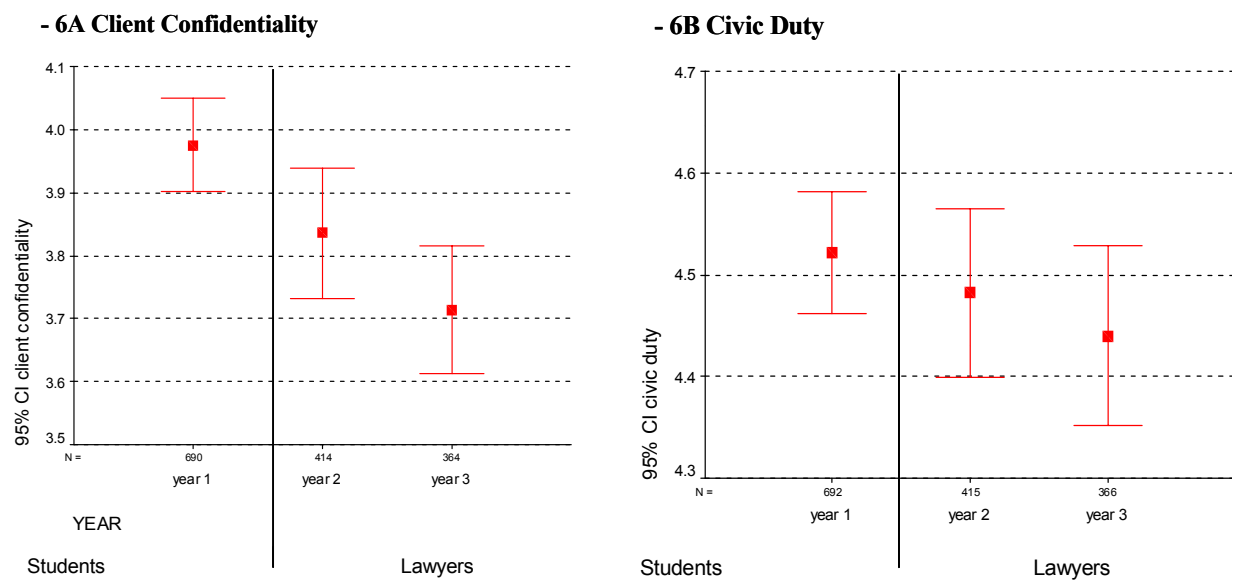

Trends in Figure 6 suggest that respondents changed their minds about the relative importance of these values from that originally reported in Year 1, although the degree of shift in the two sets of means was more noticeable in relation to client confidentiality. Whilst respondents (as students), overvalued these BRV's in relation to the initial decision in this scenario, they deemed them less important as they experienced work and further study. In the case of the BRV 'civic duty', the combination of the high Kappa coefficient (at .33) and the slight decline on the relevant means, could indicate that while 'civic duty' dominated the decision to report the potential abuse, that report would be occurring against a slight softening of conviction about the extent of 'civic duty'.

The results from this scenario were of considerable concern. The issue of child abuse is one of very high profile in Australia. The deaths of young 
children at the hands of their fathers or males known to their mothers, comprise regular features of metropolitan newspapers. Nevertheless, confidentiality has been described as one of the 'core values' of the Australian legal profession ${ }^{27}$ and, despite some policy concerns which now question the utility of confidentiality in achieving just results in the trial process, client confidentiality remains undeniably crucial as a lynch pin of common law systems of representation ${ }^{28}$. However, it was not surprising that approximately 60 percent of participants in year 1 indicated that they would break client confidentiality. In preliminary discussions about the year 1 findings we attributed this finding to the fact that these respondents had not then, for the most part, experienced the realities of legal practice and in particular, the trust ordinarily placed in lawyers by their clients. Having said that, we had not expected the steady increase of this behavioural choice, nor the degrading of the importance of the value of 'client confidentiality' over time.

A longitudinal cheapening of concern for client confidentiality is a most serious finding. This may be due to the extreme nature of the scenario, or to a larger than expected disenchantment with the value of confidentiality in any event. Further work on this finding is justified because of its extreme consequences for the utility of legal representation.

\section{Discussion}

This study aimed to investigate the extent to which reported ethical behavioural choices would be reinforced or degraded over time. It also sought to explore the characteristics of the value bases which may be salient to the decision-making process in relation to choices about ethical dilemmas. Results of this study demonstrated first that, in general, behaviour aligned with ethical codes of conduct was reinforced over time. The exceptions here were the Pro Bono and Client Confidentiality scenarios. Secondly, results suggested that certain behaviour relevant values may develop or degrade over the first years of the Australian lawyers' early career.

Whilst the majority of participants indicated behavioural choices in scenarios that could be considered aligned to professional codes of conduct, the numbers of participants in year 3 of the study, that is, in their second year in a

\footnotetext{
${ }^{27}$ Ian Dunn, former CEO, Law Institute of Victoria, 'Incorporation and MDP's' (2000) 74(9) Law Institute Journal 3.

${ }^{28}$ See Prince Jefri Bolkiah v KPMG (a firm) [1999] 2 WLR 215, 266 (Lord Millett).
} 
professional role, who reported behavioural choices that could be in opposition to professional codes of conduct, was still surprising. This was particularly true for the ethical dilemmas associated with the Pro Bono, Trust Deficiency and Rounding up Hours scenarios. Despite an increasing trend in 'ethical' behavioural choices over the course of the study, 40 percent of the sample in year 3 indicated they would not report the trust deficiency, and would round up hours to the nearest one hundred, if asked to do so. This proportion is far too high and suggests that there is no basis for sanguine assessments of the effect of peer supervision in the development of appropriate ethical attitudes. Legal practice does not necessarily make up for the (perceived) failures of undergraduate legal ethics education.

Females were more likely to indicate their choices to: undertake pro bono work in Scenario 1; report their nephew in the Scenario 3; refrain from purchasing shares on the basis of inside knowledge in Scenario 4; refrain from rounding up hours in Scenario 8; and break client confidentiality in Scenario 11. These results are consistent with earlier studies about gender difference and suggest that women may be more inclined towards ethical behaviour aligned with professional codes of conduct, although confidentiality is again a clear exception. However given that women are under-represented in leadership positions in the legal profession, more research is required to untangle the effects of social desirability (that is, the propensity to respond in ways that are aligned to socially sanctioned norms and behaviour) from gender. A limitation of this study was our inability to distinguish participants' reported behaviour from these social effects. The gender differences evidenced here could therefore be a consequence of greater social desirability effects on female students' responses, as they aim to 'fit in' with an idealised version of the professional lawyer ${ }^{29}$. While considering these cautions, the results do appear compelling, in that they confirm prior studies of gender differences that suggest that women place more importance on relational rather than individualistic characteristics in forming their vocational identity. ${ }^{30}$

The analysis of changing value bases over time was illuminating in relation to the influence of work environments on the new graduate. Results showed that there was a greater level of agreement between perceptions about the

\footnotetext{
${ }^{29}$ For discussion about the effects of value incongruence on marginality for women in organisations see Giuseppina Palermo (2005). Gender and Organisational Culture: Relationships between Marginality and Women's Career Success, Unpublished PhD Thesis, Victoria University of Technology, Melbourne.

${ }^{30} \mathrm{C}$ Gilligan, In a Different Voice: Psychological Theory and Women's Development (1982).
} 
importance of behaviour relevant values in Year 2 and 3, than between Year 1 and 3. This suggests that graduates were influenced by their work environments after they departed from the law school to such a degree as to change the value bases upon which they based their decisions making in ethical dilemmas. This result is by no means trivial. It suggests that there are powerful forces in workplace environments that influence the value bases that early career lawyers may use to work through ethical dilemmas.

This study is of course limited by its quasi-experimental design which relies on perceptions and reported behaviour on hypothetical rather than real situations. However, given that the same people were followed through their transition from law graduate to early-career law professional, the change evident in values related to scenarios may also reflect changes related to their practice of law. These findings, taken together, do not reflect well on any efforts of law schools to inculcate a 'justice ethic' within the basic law degree. Similarly, this study provides, we think, cogent evidence that the Australian profession does not appear to be active in addressing ethically appropriate attitudes in its new entrants. However, the results give some insight to which values are important for early career law professionals in their decision making process when challenged with ethical problems. While more research is justified to understand the predictive power of behaviour relevant values, these analyses may prove useful as a starting point for developing inclusive curricula in relation to explicit values and ethics education in law programs.

It is an inescapable conclusion of our research that Australian lawyers' underlying values systems, whether developed years before admission to practice or belatedly, under the influence of an often positivist undergraduate legal education, ${ }^{31}$ are powerful determinants of the attitudes that lawyers bring

\footnotetext{
${ }^{31}$ Margaret Thornton, 'The Demise of Diversity in Legal Education: Globalisation and the New Knowledge Economy' (2001) 8(1) International Journal of the Legal Profession 37. Consider Thornton's pungent multiple, assassinations of (Australian) legal education: 'Lawyers are very adroit in taking refuge behind the principle of agency, the technocratic veneer of legal doctrine and universalised language so as to denude their handiwork of moral content, while fashioning a course of action to evade or effect minimal compliance with local laws. Such strategies conduce to what Peter Fitzpatrick percipiently refers to as the "innocence of law".' (40-1) 'Corporatisation and globalisation have numbed ethical sensibilities so that the evaluation of social goods solely in market terms has become normative ... This fragmentation and indifference is fostered by global lawyering with its focus on a 'fly-in, fly-out' method of service delivery...' (41) 'Legal positivism endeavours to mask the dilemmas of practice by drawing a line of demarcation between law and morality...Legal practice becomes bearable if it can be conceptualised as no more than a series of rules, game
} 
into practice. Conventional tertiary legal ethics education may have a minor impact only, before situational cultures within each workplace then take over, often cementing prior attitudes and producing a dazzling array of behaviours, of varying ethical distinction.

\section{Values awareness as an Educational Strategy}

If lawyers' values are in need of improvement, we must seek ways and means to encourage that maturity. We think it likely that values education can 'transform' legal ethics education to make it more effective. Unmitigated transformation is most unlikely, but a values awareness process (where the teacher expresses their own views at the end of the process and then only in the context of respect for divergent views) can, we think, improve the chances of law students and lawyers understanding their own values base and their potential choices, before they are under too much pressure to make quick decisions that might be ethically suspect. ${ }^{32}$

Our sense of it is that a useful methodology for legal ethics education (as a whole) would be, firstly an exposition of some of the main ethical methods ${ }^{33}$ available for consideration as decision-making frameworks. They may differentiate between the following four types:

- the 'zealous advocate' - who identifies the client's instructions as their own ethical justification;

- the 'responsible lawyer' - who pines for the nobility of legal practice by devotion to 'the rules';

- the 'moral activist' - who can see ethics in either of the above ways, so long as justice is accessed and clients prevailed upon to take a moral course of action; and

plays or set pieces. The technocratic has always been a nifty mechanism for occluding the violence of law, a project in which a doctrinally legal education has been complicit.' (41-42).

${ }^{32}$ The pressure to make quick ethical decisions is one of the most difficult challenges for modern lawyers. David Luban has written on the potential for corruption of ethical judgment when a vulnerable lawyer is required by a superior to decide something not in a considered way, but immediately and without the benefit of reflection. See David Luban, 'The Ethics of Wrongful Obedience' in D Rhode (ed) Ethics in Practice (2000) 94-120.

${ }^{33}$ A most useful classification has been developed by Christine Parker, 'A Critical Morality for Lawyers: Four Approaches to Lawyers Ethics' (2004) 30(1) Monash Law Review 49. 
- the 'ethicist of care' - for whom 'relationship' and covenant are more important than impersonal justice and the value of law and other roles is derivative from relationships.

When these framework options are explained, people begin to consider which characterisation (or mixture thereof) might intuitively be appropriate for them. Secondly, hypothetical but realistic practice scenarios (such as those used above) are placed in front of a group of students or lawyers and the instructor asks if any one has seen anything or heard of anything similar in their work experience or practice environments? This method is often compelling for participants because of its potential to slip over their ethical 'horizon', allowing them to observe and reflect upon what they would each do in a similar situation. In many cases, people discuss what they have already done and the discussion builds from there, leading to a discussion of their preferred ethical model (as described above). If this process is effective, it is not necessary to define a 'correct' answer. Often, there is none. Students' own discussion tends to raise the various competing moral issues, and the crucial identification, or self-awareness, as to personal preferences in values through these ethical methods comes only near the end of this stage.

The third methodological phase could utilise empirical work on actual values preferences and intentional choices, ${ }^{34}$ with results from large-scale survey of lawyers, such as this one, displayed graphically for each scenario (as above) and the instructor invites individual participants to discuss how these results differ from their own answers. This is often a moment of great surprise for participants and a 'teachable moment' to be discussed. Fourthly, a 'de-brief' discussion then occurs about the applicable rules of conduct and the choice of ethical method with which they, as individual students/lawyers, feel most comfortable. Lastly, an invitation is extended to participants to consider where they might stand, in the light of these preferences, when the issues in the scenarios come before them. There is no guarantee offered here. The approach may simply make it harder for some anti-social law firm cultures to take over.

\footnotetext{
${ }^{34}$ For Australia, see Adrian Evans and Josephine Palermo, 'Lawyers' Perceptions of their Values: An Empirical Assessment of Australian Final-Year Undergraduate Law Students - Some Interim Results - 2001' (2003) 5 Legal Ethics 1\&2, 102.
} 


\section{CONCLUSION}

Specific law student values and the needs of student 'groups', require more specific attention in curricula than has been the case to date. ${ }^{35}$ Value change is possible only when discrepancies are presented that threaten self cognition. It is only then that self motivation is enhanced or threatened. Awareness of discrepancies between values related to the self concept and values prescribed as preferable through ethical and professional codes of conduct lead to dissatisfaction and dissonance and a process of change to cognition and behaviours. Law students and early-year practitioners are likely to benefit from the staged exposure presented above to their own ethical biases and encouragement to adopt 'ethically aware' processes in their future legal careers. The community at large (generally quite sceptical of lawyers' ethics and, to a lesser extent, of the rule of law) is also likely to benefit from that enhanced consciousness. In short, values awareness is likely to be a more productive route for legal ethics education.

Further, upon admission to practice, new lawyers continued and systematic reflection upon ethical choices is now, we think, also demonstrated as a necessity. We speculate that complacency about lawyers ethical development in situ will amount, before too long, to rejection of internal quality controls, of professional standards schemes' risk management regimes and of the terms of some professional indemnity insurance policies. Internal law firm programmes of values awareness, such as those we describe above, will help to negate this possibility.

\footnotetext{
${ }^{35}$ Milton Rokeach and Sandra J Rokeach, 'Stability and Change in American Value Priorities 1968-1981' (1989) 44(5) American Psychologist 775-785.
} 